\title{
HAIR DEPIGMENTATION AND DERMATITIS - AN UNEXPECTED PRESENTATION OF CYSTIC FIBROSIS
}

\author{
Milankov $\mathrm{O}^{1,2, *}$, Savic $\mathrm{R}^{2}$, Tosic $\mathrm{J}^{2}$
}

\begin{abstract}
*Corresponding Author: Professor Olgica Milankov, Novi Sad Medical Faculty, University of Novi Sad, Serbia; Institute of Child and Youth Healthcare of Vojvodina, Pediatric Clinic, Hajduk Veljkova 10, 21000 Novi Sad, Serbia; Tel.: +381641376735; Fax:+38121500433; E-mail: olgicamilankov@ gmail.com
\end{abstract}

\begin{abstract}
Hair depigmentation is very rare presentation of cystic fibrosis (CF). We present 3.5-month-old female patient who had dermatitis and depigmentation of hair and eye lashes, malnutrition, edema and anemia as presenting symptoms of CF. After pancreatic enzyme and vitamin supplementation therapy, skin changes gradually disappeared, and her hair regained its normal brown colour.
\end{abstract}

Keywords: Hair depigmentation; Cystic fibrosis (CF); Dermatitis.

\section{INTRODUCTION}

Cystic fibrosis (CF) is an autosomal recessive disease, caused by defects in the cystic fibrosis transmembrane conductance regulator (CFTR) gene that result in multi-organ dysfunction. It is the most common life-limiting genetic condition in the Caucasian race, with an incidence of 1:1353 to 1:4700 in Europe (1). Before the era of newborn screening for CF, patients were mostly diagnosed from repeated respiratory infections, failure to thrive, gastrointestinal symptoms, and high concentration of sweat chloride, which are the most common clinical presentations of

\footnotetext{
${ }^{1}$ Department of Pediatrics, Novi Sad Medical Faculty, University of Novi Sad, Novi Sad, Serbia

${ }^{2}$ Department of Infant and Small Children Pathology, Pediatric Clinic, Institute of Child and Youth Healthcare of Vojvodina, Pediatric Clinic, Novi Sad, Serbia
}

CF. Protein-energy malnutrition (with anemia, hypoproteinemia and edema) is seen in 5.0 to $13.0 \%$ of infants with CF, or in up to $33.0 \%(2,3)$. Skin involvement such as dermatitis is rare, and has been associated with deficiencies of dietary zinc, protein, and essential fatty acids $(4,5)$. Graying of hair is very rare presentation of $\mathrm{CF}$, with only three cases described in the literature $(4,6,7)$.

Case Report. A 3.5-month-old female was admitted to our department for aspiration pneumonia. She was born at term, the second surviving child of unrelated Serbian parents, with satisfactory social status. Another pregnancy had ended with the fetus dying in utero after 8 months, while a surviving sibling was healthy. During the pregnancy, the mother was on a low-molecule heparin therapy, due to congenital thrombophilia, and was anemic. There was a family history of atopy. At birth, the child had a body weight of $3.91 \mathrm{~kg}$, length $51 \mathrm{~cm}$. She was fed a mixed diet of breast milk and milk formula. Growth in body weight was $0.81 \mathrm{~kg}$. Stools were fatty, smelly, abundant. Because of anemia she received a blood transfusion when she was 1-month-old, and has been receiving iron therapy ever since. Eczematous dermatitis on the lower extremities appeared at 2 months of age, and was treated with neutral cream. Seven days before the admission, she had an episode of choking after feeding and followed by an intensive and persistent cough.

On admission to hospital she was alert, hypotonic, with rectal temperature of $38^{\circ} \mathrm{C}$, respiratory rate $50 / \mathrm{min}$., pulse rate $110 / \mathrm{min}$. Body weight $4720 \mathrm{~g}$ ( 10 th centile), body length $53 \mathrm{~cm}$ (10th centile). Hair 


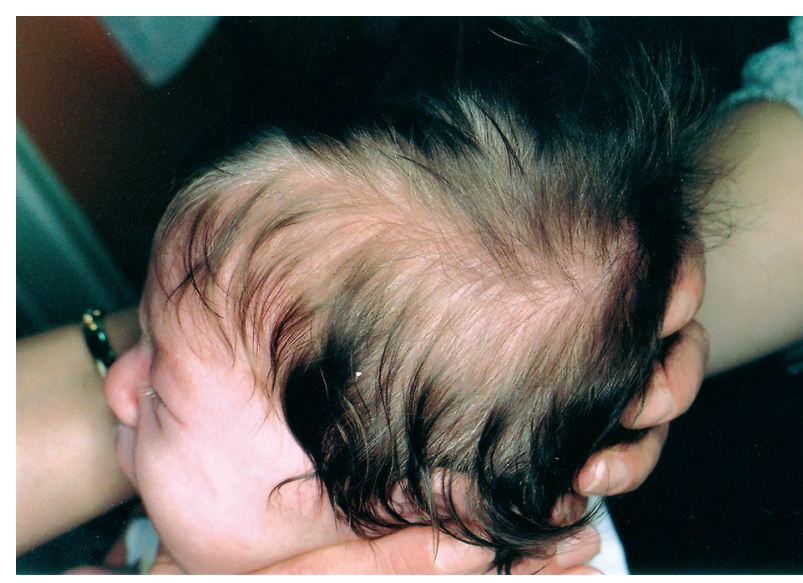

Figure 1. Hair and eye lash changes at presentation.

and eye lashes were depigmented in the proximal parts (Figure 1). Hyperpig-mentation of skin, with laminar peeling and red borders, was present on face and lower extremities. Skin of inguinal and popliteal regions was red and desquamated (Figure 2). There was a serous secretion in nose and thrush in the mouth cavity. Liver was palpable $2.5 \mathrm{~cm}$ under the right costal arch but the spleen was not palpable. There was an edema of the lower legs.

Laboratory tests revealed elevated sedimentation rate $(20 \mathrm{~mm} /$ hour $)$, and elevated C-reactive protein (12 $\mathrm{mg} / \mathrm{L})$. Leucocytes $9.08 \times 10^{9} / \mathrm{L}(52.0 \%$ neutrophils, $48.0 \%$ lymphocytes), platelets $265 \times 10^{9} / \mathrm{L}$. She had normocytic anemia $(\mathrm{Hb} 7.1 \mathrm{~g} / \mathrm{dL})$ and hypoalbuminemia $(18.6 \mathrm{~g} / \mathrm{L})$. Transaminases were slightly elevated [aspartame amino-transferase (AST) $1.20 \mu \mathrm{kat} / \mathrm{L}$ (normal 0.27-1.01), alanine aminotransferase (ALT) 1.41 $\mu \mathrm{kat} / \mathrm{L}$ (normal 0.20-0.80)]. Gamma glutamyl transferase (GGT) $5.05 \mu \mathrm{kat} / \mathrm{L}$ (normal 0.22-2.05). Total immunoglobulin E (IgE) 103.6 IU/mL (normal 0.0-24.0). Fat droplets were present in the stool. Chest X-ray showed right-sided pneumonia. Esophageal radiography revealed gastroesophageal reflux. Two consecutive sweat tests showed chloride concentration of $99.0 \mathrm{mmol} / \mathrm{L}$, $87.0 \mathrm{mmol} / \mathrm{L}$ (normal 0.0-40.0), and the patient was diagnosed with CF. Genetic analysis was performed at the Institute of Molecular Genetics and Genetic Engineering in Belgrade, Serbia. The CFTR gene showed a $\delta$-F508 mutation in the homozygous state.

Treatment included parenteral antibiotic and anti-gastroesophageal reflux therapy. After initiation of pancreatic enzymes and vitamin supplementation therapy, skin changes gradually disappeared, and her hair regained its normal brown color.

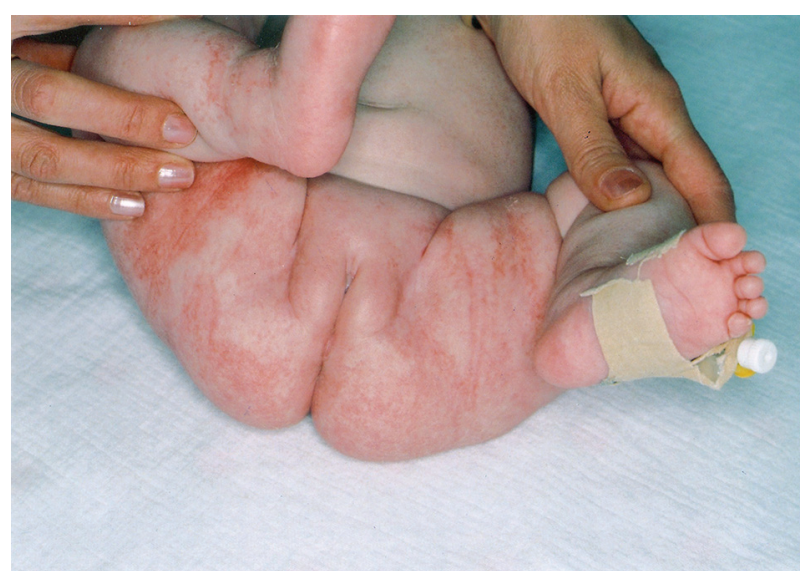

Figure 2. Skin changes at presentation.

\section{DISCUSSION}

Dermatitis as a presenting symptom of CF seems rare and has been previously reported in 24 other patients (5). However, the incidence of this presentation of CF is likely higher because of unreported cases. The pathophysiology of the cutaneous symptoms of CF is unclear but it is thought that lack of protein, zinc and essential fatty acids (especially linolenic acid) play a role $(8,10-12)$. The hypo-proteinemia, zinc and essential fatty acid deficiency are due to malabsorbtion in $\mathrm{CF}$ and secondary to pancreatic failure.

The rash typically appears in infancy, from age 2 weeks to 15 months. The eruption usually begins in the diaper area, has a predilection for the perioral area and the extremities, and can extend to cover the entire body. The initial eruption consists of erythematous, scaly papules and progresses within 1-3 months to extensive, desquamating plaques $(5,7,8,12)$. Vesicles, bullae and pustules can also occur. In our patient, the rash appeared at 2 months of age as an eczematous dermatitis on the lower extremities. Because of the history of atopy in our patient's family, her rash was diagnosed as atopic dermatitis and treated with H1receptor antagonists, neutral cream and hypoallergenic infant formula. Despite the therapy, skin lesions extended on to the face, arms and trunk and desquamating plaques in the inguinal and popliteal regions.

Regarding hair depigmentation as a presenting symptom of CF, the hair of patients in two reviewed cases $(6,7)$ was completely gray. In a third case (4), there was hypo-pigmentation of the proximal $1 \mathrm{~cm}$ of scalp hair as in our patient, together with the depigmentation of the eye lashes at the proximal parts. 
The hypopigmentation of hair probably results from a combination of nutritional deficiencies. It has been shown that lack of the amino acid tyrosine and coenzymes required for the synthesis of pigments in the hair and skin, result in changes in the hair color and hyper-pigmentation of skin in protein-energymalnourished children (9).

Elements of the rash observed in CF resembled the skin lesions found in protein-calorie malnutrition, essential fatty acid deficiency, and acrodermatitis enteropathica (AE), an autosomal recessive defect causing primary zinc deficiency. Severe protein malnutrition can lead to skin changes consisting of erythematous plaques, desquamation, stomatitis, glossitis, thinning nails and alopecia. Deficiency in fatty acid, especially linoleic, is associated with periorificial cutaneous eruptions consisting of dry, thickened, erythematous and desquamating plaques (12). In the reviewed literature $(4-8,10,11)$, all patients had normal mucous membranes and nails, like our case, contrary to what is seen in AE patients. The differential diagnosis of this type of rash beside AE, protein-energy malnutrition, biotinidase deficiency, also includes psoriasis, seborrheic dermatitis, atopic dermatitis, Langerhans cell histiocytosis, epidermolysis bullosa and immunodeficiency syndromes such as WiscottAldrich syndrome, Netherton's syndrome and severe combined immunodeficiency $(4-8,10-12)$.

Declaration of interest: The authors report no conflicts of interest. The authors alone are responsible for the content and writing of this paper.

\section{REFERENCES}

1. Salvatore D, Buzzetti R, Baldo E, Forneris M, Lucidi V, Manunza D, et al. An overview of international literature from cystic fibrosis registries. Part 3. Disease incidence, genotype/phenotype correlation, microbiology, pregnancy, clinical complications, lung transplantation, and miscellanea. J Cyst Fibros. 2011; 10(2): 71-85.

2. Nielsen $\mathrm{OH}$, Larsen BF. The incidence of anemia, hypoproteinemia, and edema in infants as presenting symptoms of cystic fibrosis: A retrospective survey of the frequency of this symptom complex in 130 patients with cystic fibrosis. J Pediatr Gastroenterol Nutr. 1982; 1(3): 355-359.

3. Fustik S, Jacovska T, Spirevska L, Koceva S. Protein-energy malnutrition as the first manifestation of cystic fibrosis in infancy. Pediatr Int. 2009; 51(5): 678-683.

4. Darmstadt L, McGuire J, Ziboh A. Malnutritionassociated rash of cystic fibrosis. Pediatr Dermatol. 2000; 17(5): 337-347.

5. Wenk K, Higgins K, Greer K. Cystic fibrosis presenting with dermatitis. Arch Dermatol. 2010; 146(2): 171-174.

6. Mei-Zahav M, Solomon M, Kawamura A, Coates A, Durie P. Cystic fibrosis presenting as kwashiorkor in a Sri Lankan infant. Arch Dis Child. 2003; 88(8): 724-725.

7. Dalgic B, Egritas O. Gray hair and acrodermatitis enteropathica-like dermatitis: an unexpected presentation of cystic fibrosis. Eur J Pediatr. 2011; 170(10): 1305-1308.

8. Lovett A, Kokta V, Maari C. Diffuse dermatitis: An unexpected initial presentation of cystic fibrosis. J Am Acad Dermatol. 2008; 58(2): S1-S4.

9. Oshikoya KA, Senbanjo IO. Pathophysiological changes that affect drug disposition in proteinenergy malnourished children. Nutrit Metab. 2009; 6(1): 50-57.

10. Phillips RJ, Crock CM, Dillon MJ, Clazton PT, Curran A, Harper JI. Cystic fibrosis presenting as kwashiorkor with florid skin rash. Arch Dis Child. 1993; 69(4): 446-448.

11. Crone J, Huber WD, Eichler I, Granditsch G. Acrodermatitis enteropathica-like eruption as the presenting sign of cystic fibrosis-case report and review of the literature. Eur J Pediatr. 2002; 161(9): 475-478.

12. MunizAE, Bartle S, Foster R. Edema, anemia, hypoproteinemia and acrodermatitis enteropathica: an un-common initial presentation of cystic fibrosis. Pediatr Emerg Care. 2004; 20(2): 112-114. 